\title{
Zur Semidecussation im Chiasma nerv. opt. des Menschen.
}

\author{
Von \\ Dr. R. Deutsehmann.
}

Das Präparat, welches die Gelegenheit zu der nachfolgenden Untersuchung gab, entstammt der hiesigen Provinzial-Irrenanstalt *); ich erhielt es frisch in Müller'seher Flüssigkeit eingelegt.

Patient, um dessen Augen es sich handelt, hatte den rechten Bulbus vor 40 Jahren, wodureh, ist mir unbekannt, eingebüsst; derselbe stellte zur Zeit seiner Beobachtung in der Irrenanstalt einen kleinen, phthisischen Stumpf dar; das linke Auge war intact.

Das mir von der Section gütigst überlassene Präparat besteht aus: rechtem Bulbus, den Nervis opticis, Chiasma und den Tractus opt. bis zu den Corpor. geniculata.

Der linke Nervus opticus ist an dem Präparate nur vom Foramen opticum (centralwärts) erhalten; or ist hier nahezu von doppelter Dicke, als der rechte. Die Tractus dicht hinter dem Chiasma scheinen beide etwas dünner als normal, dor linke aber entschieden dünner als der rechte. Die von mir ausgeführten Cirkelmessungen ergaben:

Rechter Opticus am Foram. opt. 3 und 1,5 Mm.

Linker " " " $, 5,5,3 \mathrm{Mm}$.

*) Ich verdanke es der Güte des Herrn Dr. R. Kohn, damal. 1. Assistent der Anstalt. 
Rechter Tractus dicht hinter dem Chiasma 4 und $2,75 \mathrm{Mm}$. Linker " " " $\quad " \quad 3 \quad, 2,5$ "

Der rechte Bulbus, bohnengross (Durchmesser 12 und $9 \mathrm{Mm}$.), total phthisisch, wird im horizontalen Meridian durchschnitten; die Cornea erweist sich verdünnt, die Sclera ausserordentlich verdickt; in der Mitte des Bulbus ist ein ron dunklem Pigment umsäumter Hohlraum, mit verschiedenen divertikelartigen Ausläufern. Nach hinten bildet die Begrenzung dieses Hohlraums ein Gewebe, das Opticus und abgelöste Retina zu repräsentiren scheint.

Mikroskopisch zeigt sich die Hornhaut zum Theil durch feines Narbengewebe ersetat, hie und da pannös, von feinen und feinsten Gefässen durchzogen; Membrana Descemeti theilweis erhalten. Der hintern Hornhautwand liegt fest eine dünne Lage eines kernreichen Fasergewebes an, dieser wieder eine unregelmässige Pigmentschicht. Die Stelle der Ciliargegend nimmt ein nach dem Bulbusinnern hin von Pigment begrenztes, stark kernhaltiges Fasergewebe ein. Der Hohlranm, der das Bulbusinnere vertritt, ist von unregelmässigen Pigmentklumpen umsäumt resp. ausgekleidet, die hie und da Inseln sehr zellenreichen Gewebes, das in den Bulbrusraum vorspringt, einschliessen. Von Linsensubstanz ist nichts vorhanden; an ilhrer Stelle ohngefähr eine zarte Lage einer feinkrümelig geronnenen Masse mit einigen wenigen Vacuolen haltigen Zellen. Nach hinten schliesst den Bulbus ein kolbenförmiges Gebilde $a b$, dessen Centrum aus einem derben Faserstrang besteht, um welchen herum Körnermassen in einer Andeutung von Retinalschichtung liegen; daran schliesst sich seitlich (d. h. nach anssen hin) ein derbes Fasergewebe, das Stïckchen echten Knochens enthält; daran weiter nach anssen pigmentirtes Bindegewebe, endlich enorm verdickte Sclera mit auffallend starken and reichlichen Ciliarnerven. Nach hinten geht dies kolbenförmige Gebilde in den total atrophirten Nervus opticus über.

Der rechte Opticusstamm ist bis zum Foram. opticum hin in seiner ganzen Dicke atrophisch; er stellt ein in Carmin durchaus gleichmässig gefärbtes, reichlich kernhaltiges (wohl nur relativer Kernreichthum) Fasergerïst dar, in dem sich kein Rest von Nervenfasern finden lässt. Auffallend erscheinen die Blutgefässe des atrophisehen Opticusstammes durch eine sie umgebende Lymphscheide, die von regular, dicht aneinander 
stehenden Zellen epitheloider Natur ausgefüllt ist. Die äussere Sohnervenscheide ist schlaff, dabei aber stark verdickt, so dass der Umfang des Opticus am Foramen selerae nahezu normale Durchmesser zeigt. Vom Foramen opticum an centralwärts lassen sich allmälig hie und da, besonders in der äusseren Hälfte des Opticus, Reste von Nervenfasern nachweisen, dann einige wenige in der unteren und oberen Parthie desselben; dicht vor dem Chiasma zeigt der Opticusquersehnitt das Bild
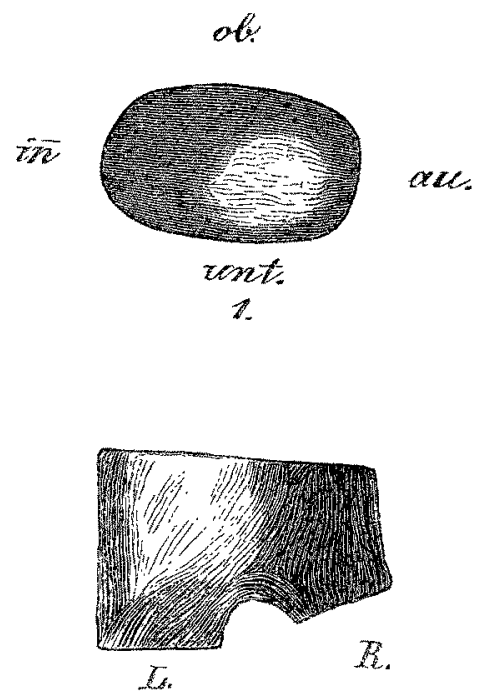

2

Figur 1, in dem die schraffirten Parthieen die Atrophie darstellen. Es ergiebt sich daraus, dass hier die hauptsächlich atrophischen Theile nach oben und innen, die relativ erhaltenen nach unten und aussen sich befinden.

Der linke Opticusstamm ist normal. - Das Chiasma wurde in eine vordere und hintere Hälfte zerlegt; die vordere wurde horizontal, die hintere quer geschnitten. Figur 2 repräsentirt einen besonders charalteristischen Horizontalschnitt, der nicht genau der Mitte des Chiasmas entnommen ist, sondern etwas in die untere Hälfte desselben fällt; es zeigt hier die linke Hälfte eine auffallend starke Atrophie des inneren (gekreuzten) 
Faserbündels, die rechte eine geringe, durch die von links herüberkommenden intacten Nervenfasern etwas verdeckte seiner inneren, unteren Bündel. (In der Figur ist der hell gelassene Theil der atrophische, während die normalen Fasern gezeichnet sind.) Eine bessere Orientirung über die Art der Atrophie im Chiasma gaben die Quersehnitte durch die hintere Hälfte des Chiasma. Zunächst erwies sich, dass die linke Hälfte bemerklich dünner war, als die rechte, ein Verhalten, das sich
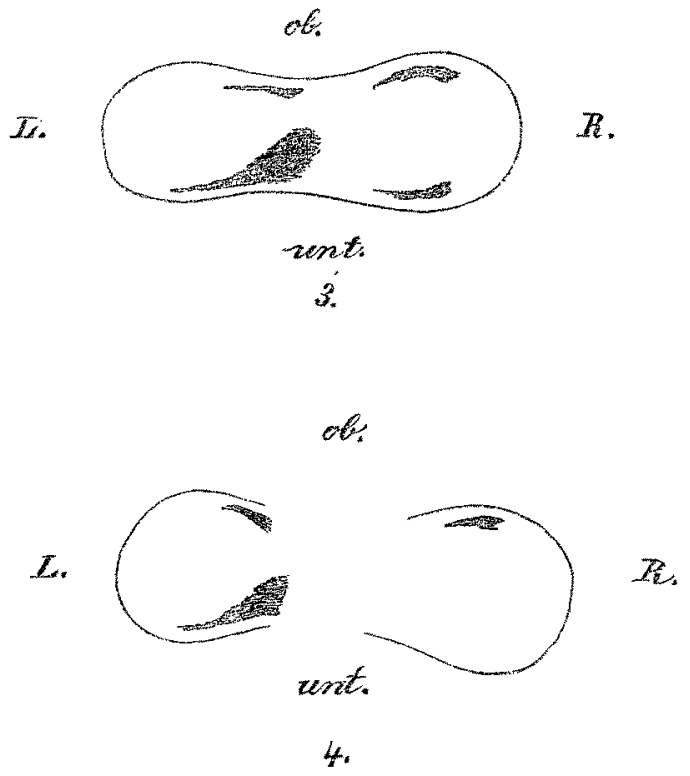

weiterhin auf die Tractus fortsetzte. Figur 3 giebt ein Bild des Querschnittes durch das Chiasma in seiner hinteren Hälfte; die atrophisehen Parthien sind in der Figur schraffirt: Stärkste Atrophie: links innen und unten, geringe Spuren oben; ebenso geringe atrophische Parthieen: rechts oben und unten.

Querschnitte- durch die Tractus optici erweisen immer beide als partiell atrophisch und zwar den gekreuzten linken stärker als den zum atrophirten Nerven gehörenden gleichseitigen rechten. Die Figur 4 giebt ein Bild der Verhältnisse durch einen Quersehnitt, der in geringer Entfernung vor den 
Corp. genicul. angefertigt ist. Links: Atrophie: innen und unten, sehr wenig: oben; rechts: nur sehr wenig: oben. In der Höhe der Corpora genieul. hört jede nachweisbare Atrophie auf, nachdem die allerletzten Schnitte nur noch schmalste atrophische Streifchen, im linken Tractus, nach oben und anten, im rechten nur nach oben mit Mähe erkennen liessen.

Zum Nachweise der atrophischen Parthieen wurde Goldchlorid, Jodviolett und Carmin benutzt; doch erwies sich das ungefarbte Präparat als das markanteste.

Es hatte also nach dem pathologischen anatomischen Befunde zor Folge: Einseitige Opticusatrophie, Atrophie beider Tractus; die Opticus-Entartung war kurz vor dem Chiasma nicht mehr total; sie zeigt sich in beiden Tractus nur partiell und zwar im gekreuzten stärker, als im gleichseitigen. Die Hauptatrophie sitzt im rechten Nervus opticus nach innen, weiter nach oben, dann oben aussen, am wenigsten nach unten und unten aussen; die Hauptentartung. findet sich im linken Tractus nach innen, dann ziemlich gleichmässig nach oben und unten; im rechten nach oben und unten, schliesslich nur noch nach oben. 